\title{
Sleep apnoea syndrome caused by neurofibromatosis and superior vena caval obstruction
}

\author{
JR STRADLING, S HUDDART, AG ARNOLD \\ From the Chest Clinic, Churchill Hospital, Oxford
}

Superior vena caval (SVC) obstruction is usually caused by malignant conditions but benign causes have been reported in as many as $26 \%$ of cases $^{12}$ We describe a patient with mediastinal neurofibromata who developed SVC obstruction, upper airways oedema, and gross sleep apnoea syndrome. ${ }^{3}$ We can find no previously documented cases of sleep apnoea caused by SVC obstruction.

\section{Case report}

A 73-year-old man had been attending the Chest Clinic for 16 years with progressive chronic airways obstruction caused by smoking. Upper mediastinal shadows first noticed in 1945 after a chest radiograph had been proved histologically to be neurofibromata after thoracotomy. In 1976 his collar size increased and signs of SVC obstruction were first recorded. At this time his FEV $_{1}$ had dropped to 0.9 litres. In 1978 he began to complain of excessive sleepiness and poor concentration during the day. His diuretic therapy was increased and these symptoms abated. Two months before his current admission (1980) his collar size had increased from 17 to 20 inches Over this time he became overtly hypersomnolent with poor concentration. He had injured himself on several occasions by falling out of a chair while asleep. Further questioning revealed that he had always been a loud snorer, but this had become more marked recently, with very restless and disturbed sleep. The daytime symptoms were distressing him and his family.

Examination revealed signs of SVC obstruction with very distended neck veins, facial swelling, and a neck circumference of 19 inches. He was a little overweight $\left(\frac{\mathrm{W}}{\mathrm{H}^{2}}=25 \cdot 5\right)$. His $\mathrm{FEV}_{1}$ and FVC were 0.7 and $2 \cdot 1^{1}$ respectively. There was no ankle oedema.

A chest radiograph showed no change in the size of the mediastinal masses since 1976. Lateral neck views showed increased soft tissue shadowing throughout the pharyngeal region (in particular soft palate and posterior pharyngeal wall). A lateral cervical spine view taken 11 years previously just included the posterior pharyngeal wall and showed no such thickening. A superior vena cavagram carried out in 1979 had confirmed venous obstruction with the development of some collateral circulation.

Address for reprint requests: Dr JR Stradling, The Chest Clinic, Churchill Hospital, Headington, Oxford OX3 7LJ.

Resting blood gas estimations were: $\mathrm{PaO}_{2}=7 \cdot 3 \mathrm{kPa}, \stackrel{\infty}{\varnothing}$ $\mathrm{PaCO}_{2}=6.5 \mathrm{kPa}, \mathrm{SaO}_{2}=87 \%$.

He was studied overnight with the Hewlett Packard ear oximeter, nasal flow monitor, and continuous $\frac{}{I}$ observation to define the sleep apnoea. Cheyne-Stokes respiration was observed to be continuously present throughout the night. Upper airways closure obstructed

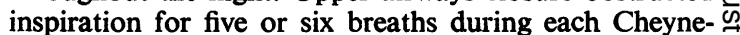
Stokes cycle as the respiratory movements returned. $\vec{\theta}$ Associated with this were large swings in arterial oxygen $\propto$ saturation (fig, top). At times it reached levels as low as. $30 \%$. On the ward he had two hypoxic epidoses when asleep in a chair, leading to convulsions and subsequent mental impairment. He therefore underwent bronchoscopy and intubation under local anaesthesia
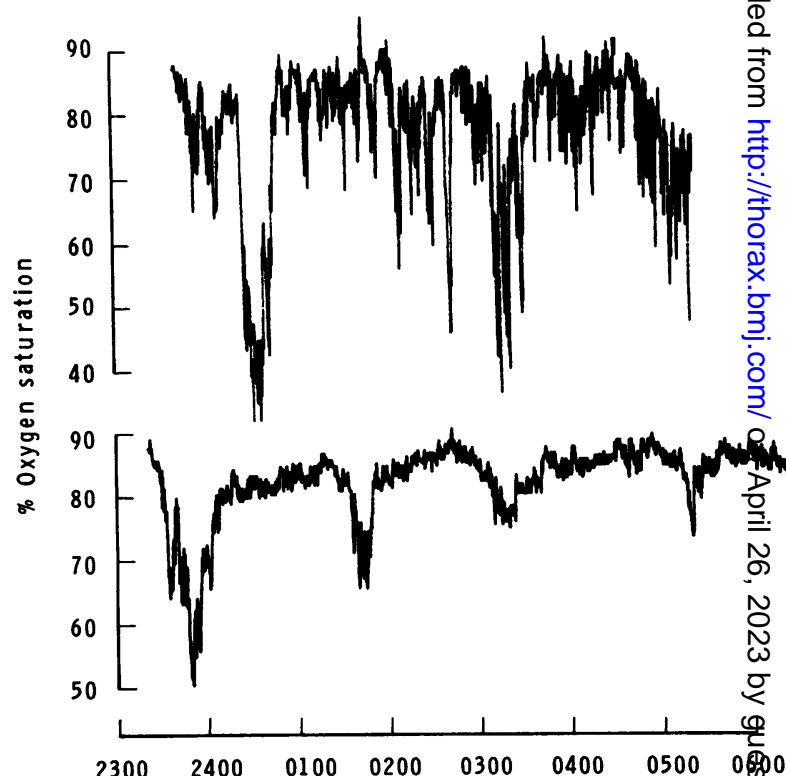

Time ( 24 hour clock)

Figure Top: pre-tracheostomy overnight oxygen saturation tracings, showing frequent dips which were associated with apnoeic episodes. Bottom: posttracheostomy tracing showing less frequent hypoxaemic episodes not associated with apnoea. 
just before a night's sleep. This was considered necessary to prove that the symptoms were caused by sleep apnoea rather than SVC obstruction per se. ${ }^{1}$ The pharynx and vocal cords were very oedematous but the major airways were normal. The patient subsequently slept undisturbed and quietly for five hours with the nasotracheal tube in place and woke with clear thought and no hypersomnolence. On the basis of this evidence a tracheostomy was performed. The patient's subsequent improvement was remarkable; his wife feels he has not been so alert for two or three years. He is coping with his tracheostomy well. The figure (bottom section) shows the overnight oximeter tracing after tracheostomy. The dips still present were not caused by apnoea and resemble those seen commonly in hypoxic patients with airways obstruction. Cheyne-Stokes respiration was still present but was very much less marked, with no apnoea as before.

\section{Discussion}

Sleep apnoea syndrome is now a well-recognised condition. In most cases no anatomical abnormality is found. $^{3}$ In our case, as in acromegaly, ${ }^{5}$ an acquired abnormality of the upper airway was responsible. The nocturnal hypoxia was partly caused by the longstanding airways obstruction but the dominant cause was upper airways obstructive sleep apnoea. The dramatic effect of nasotracheal intubation overnight in this patient parallels that described by Guilleminault in the Pickwickian patients with sleep apnoea syndrome. ${ }^{3}$
In this example of upper airways sleep apnoea it was assumed that the oedema in the pharyngeal or laryngeal airway was responsible. Several possible therapeutic manoeuvres were considered-removal of mediastinal neurofibroma, superior vena caval bypass surgery, ${ }^{1}$ tracheostomy, ${ }^{3}$ or pharyngeal surgery. ${ }^{4}$ In the event the only practical and relatively safe course seemed to be tracheostomy.

Although SVC obstruction caused by neurofibromatosis is very rare, other non-malignant causes are not. ${ }^{12}$ The insidious onset of the sleep apnoea syndrome should be remembered as a possible sequel since this is a potentially fatal condition and is remediable. ${ }^{3}$

We thank Dr DJ Lane for allowing us to study a patient under his care and $\mathrm{Mr}$ Freeland for performing the tracheostomy.

\section{References}

${ }^{1}$ Urschel HC, Paulson DL. Superior vena caval obstruction. Dis Chest 1966;49:155-64.

${ }^{2}$ Effler DB, Groves LK. Superior vena caval obstruction. J Thorac Cardiovasc Surg 1962;43:574-84.

${ }^{3}$ Guilleminault C, Tilkian A, Dement WC. The sleep apnoea syndromes. Ann Rev Med 1976;27:465-84.

${ }^{4}$ Conway W, Fujita S, Zorick F, Roth T, Hartse K, Piccione $\mathrm{P}$. Uvulo-palato-pharyngoplasty in treatment of upper airway sleep apnoea. Am Rev Respir Dis 1980;121 (Suppl):121.

5 Perks WH, Horrocks P, Cooper RA, et al. Sleep apnoea in acromegaly. Thorax 1980;35:237. 